
\title{
28 Research Square \\ Fasting Blood Glucose to High-Density Lipoprotein Cholesterol Ratio in Relation to Short-Term Outcomes in Patients with Acute Coronary Syndrome
}

\section{Simin Deng}

Second Xiangya Hospital

Zhaojun Wang

Second Xiangya Hospital

Yifeng Zhang

Second Xiangya Hospital

\section{Ying Xin}

Second Xiangya Hospital

\section{Cheng Zeng}

Second Xiangya Hospital

Xinqun Hu ( $\nabla$ huxinqun@csu.edu.cn )

second xiangya hospital https://orcid.org/0000-0003-1430-4833

\section{Research}

Keywords: acute coronary syndrome, fasting blood glucose, high-density lipoprotein cholesterol, major adverse cardiovascular events, cardiovascular death, metabolic syndrome

Posted Date: November 17th, 2021

DOI: https://doi.org/10.21203/rs.3.rs-1056228/v1

License: (c) (1) This work is licensed under a Creative Commons Attribution 4.0 International License. Read Full License 


\section{Abstract}

\section{Background}

Biochemical markers are crucial for determining risk in patients with coronary artery disease (CAD); however, the association between the fasting blood glucose to high-density lipoprotein cholesterol (FG/HDL-C) ratio and short-term outcomes in patients with acute coronary syndrome (ACS) remains unknown. We investigated the association between the FG/HDL-C ratio and 30-day major adverse cardiovascular events (MACEs) and cardiovascular (CV) death in patients with ACS.

e

\section{Methods}

We performed a post-hoc analysis of data from the Acute Coronary Syndrome Quality Improvement in Kerala (ACS-QUIK) study. A total of 11,284 patients with ACS were subdivided into quartiles according to their FG/HDL-C ratios. We used a multivariate logistic regression model, generalized additive model (GAM), and two-piecewise linear regression model to determine the association of the FG/HDL-C ratio with MACEs (death, reinfarction, stroke, and major bleeding) and CV death.

\section{Results}

The FG/HDL-C ratio was significantly associated with an increased risk of MACEs and CV death in patients with ACS in the highest quartile (MACEs, odds ratio [OR]: 1.49; 95\% confidence interval [CI], [1.11, 1.99]; $P<0.01 ; C V$ death, OR: 1.69; $95 \% \mathrm{Cl},[1.01,1.41] ; P=0.04)$. The $\mathrm{GAM}$ and two-piecewise linear regression model demonstrated that the relationship between the FG/HDL-C ratio and MACEs and CV death was non-linear (non-linear $\mathrm{P}<0.05$ ); the threshold values were 3.02 and 3.00 for MACEs and CV death, respectively.

\section{Conclusions}

A higher FG/HDL-C ratio is associated with an increased risk of MACEs and CV death in patients with ACS.

\section{Background}

Coronary artery disease (CAD) has complex pathophysiological features and is thought to be a multifactorial disease $(1,2)$. Globally, CAD contributes to one-third of deaths in people over the age of 35 years (3). In particular, among patients with CAD, acute coronary syndrome (ACS) is a serious concern because of adverse outcomes during the follow-up period, such as death, reinfarction, stroke, major bleeding, and cardiovascular (CV) death (4). 
Metabolic syndrome (MetS) is known as the major etiological contributor to CAD (5), despite the existence of several different definitions of MetS; however, these differences are minor. MetS is characterized by abdominal obesity, high blood pressure, high triglycerides (TRIG), low high-density lipoprotein cholesterol (HDL-C), and elevated fasting blood glucose (FG) (6). Moreover, each component of MetS is independently and individually associated with an increased risk of CV events and mortality (7-10). Several studies have shown that FG is strongly associated with adverse outcomes in patients with ACS, regardless of the presence of diabetes (11-13), and a low level of HDL-C is generally regarded as an independent $\mathrm{CV}$ risk factor (14).

In recent years, an increasing number of studies have investigated the association between biochemical biomarkers and adverse outcomes in patients with CAD, such as the triglyceride/HDL-C ratio (15) and triglyceride-glucose index (16). In several clinical scenarios, these markers are crucial for establishing a diagnosis, determining risk, and guiding therapy. As a comprehensive indicator, the synthesis of $\mathrm{FG}$ and HDL-C, i.e., the FG/HDL-C ratio, has seldomly been investigated. To the best of our knowledge, the association between the FG/HDL-C ratio and major adverse CV events (MACEs) and CV death in patients with ACS has not been established. Therefore, we analyzed 11,284 patients with ACS and sought to determine the association between the FG/HDL-C ratio and MACEs and CV death and discussed the effect of the FG/HDL-C ratio on MACEs and CV death in patients with ACS.

\section{Methods}

\section{Study population}

This was a post hoc analysis of data from the Acute Coronary Syndrome Quality Improvement in Kerala (ACS-QUIK) study (we obtained a limited dataset from the Biologic Specimen and Data Repository Information Coordinating Center, National Heart, Lung and Blood Institute, U.S. Department of Health \& Human Services). The protocol and results of the ACS-QUIK study have been described and published previously $(17,18)$. In brief, the ACS-QUIK study was a large, pragmatic, cluster-randomized, steppedwedge clinical trial assessing the implementation and effect of a locally developed quality improvement toolkit on 30-day MACEs in patients admitted with ACS in Kerala, India. The quality improvement toolkit consisted of audit and feedback, checklists, patient education materials, and linkage to emergency cardiovascular care and quality improvement training. From November 2014 to December 2017, the trial recruited 22,557 volunteers from 63 hospitals; of these, 21,374 were eligible, and 21,079 participants had complete outcome data. However, after adjusting for cluster and temporal trends, compared with usual care, the implementation of the quality improvement toolkit did not reduce the 30-day MACEs rates. After excluding 10,090 patients without baseline FG, HDL-C, or outcome data, we analyzed 11,284 patients in this study.

\section{Variables and definitions}

The variables we used were as follows: cohort, intervention, sex, age, heart rate, weight, systolic blood pressure (SBP), hemoglobin, creatine kinase isoenzymes in the heart (CK-MB), troponin, serum creatinine 
(sCr), HDL-C, low-density lipoprotein cholesterol (LDL-C), TRIG, FG, smoking or tobacco, hypertension, peripheral arterial disease (PAD), prior transient ischemic attack (TIA) or stroke, diabetes, ST-segment elevation myocardial infarction (STEMI), heart failure, cardiac shock, cardiac arrest, Killip class, left ventricular ejection fraction (LVEF) category $(1:<40 \% ; 2: \geq 40 \% ; 3$ : unknown or not assessed), minutes from symptom onset to arrival, minutes from door to balloon, angiography, percutaneous coronary intervention $(\mathrm{PCl})$, coronary artery bypass graft surgery (CABG), aspirin, clopidogrel, ticagrelor, betablocker, warfarin, angiotensin-converting enzyme inhibitor (ACEI), angiotensin receptor blocker (ARB), statin, MACEs, and CV death. The baseline FG and HDL-C levels were defined as the FG and HDL-C levels at the first medical contact. "Intervention" was defined as the use of the quality improvement toolkit. The primary endpoint was 30-day MACEs, defined as death, reinfarction (defined by the third universal definition of myocardial infarction (19)), stroke, or major bleeding. The secondary endpoint was 30-day CV death. "30-day" was defined from the admission to post-discharge 30-days.

\section{Statistical analysis}

All statistical analyses were performed using the statistical software packages $\mathrm{R}$ (The R Foundation, Vienna, Austria; http://www.R-project.org) and EmpowerStats (X\&Y Solutions, Inc., Boston, MA; http://www.empowerstats.com). Continuous variables were expressed as mean and standard deviation (SD) or median with interquartile range, depending on whether the data were normally distributed (assessed using normal quantile-quantile [Q-Q] plots and the Lilliefors [Kolmogorov-Smirnov] normality test). Categorical variables were reported as frequencies with percentages. To determine statistical differences between variables, a one-way analysis of variance or the Kruskal-Wallis $\mathrm{H}$ test was used for continuous variables (depending on the type of data distribution), and chi-square tests were used for categorical variables. We used multiple logistic regression models to evaluate the association between the FG/HDL-C ratio and MACEs and CV death, including non-adjusted, minor-adjusted, and fully adjusted models. We selected confounders on the basis of their clinical implications, statistically significant differences in the univariable analysis (Supplement Tables 1 and 2), and their change in effect estimate of more than $10 \%$. Both non-adjusted and multivariate-adjusted models were applied. Meanwhile, we used the FG/HDL-C ratio as either a continuous or categorical variable to evaluate the relationship; when the FG/HDL-C ratio was treated as a categorical variable, the first quartile was used as the reference. The interaction and stratified analyses were conducted according to sex, age, heart rate, SBP, smoking or tobacco, hypertension, PAD, prior TIA or stroke, diabetes, STEMI, heart failure, cardiac shock, cardiac arrest, Killip class, LVEF category, angiography, PCl, and CABG. If the equivalent degrees of freedom were $>1$, a nonlinear relationship was observed. When a non-linear relationship was determined, we used the generalized additive model (GAM) to evaluate the non-linear relationship between the FG/HDL-C ratio and 30-day endpoints. We used a two-piecewise linear regression model to calculate the threshold effect of the relationships between the FG/HDL-C ratio and 30-day endpoints. The inflection point was calculated automatically by the recursive method using the maximum-likelihood model. Different regression coefficients were found on the left and right sides of the inflection point. Finally, we used the logarithmic likelihood ratio test to evaluate whether one-line linear regression models or two-piecewise linear regression models are more appropriate for describing the data. 
Table 1

Baseline characteristics of participants.

\begin{tabular}{|c|c|c|c|c|c|}
\hline Characteristic & Q1 (n=2823) & Q2 (n=2821) & Q3 (n=2830) & Q4 (n=2810) & $\begin{array}{l}\mathrm{P}- \\
\text { value }\end{array}$ \\
\hline FG/HDL-C ratio & $1.88 \pm 0.33$ & $2.78 \pm 0.25$ & $3.80 \pm 0.37$ & $6.52 \pm 2.07$ & $<0.001$ \\
\hline Intervention & $\begin{array}{l}1222 \\
(43.29 \%)\end{array}$ & $\begin{array}{l}1436 \\
(50.90 \%)\end{array}$ & $\begin{array}{l}1429 \\
(50.49 \%)\end{array}$ & $\begin{array}{l}1405 \\
(50.00 \%)\end{array}$ & $<0.001$ \\
\hline Sex & & & & & 0.006 \\
\hline Female & 715 (25.33\%) & $684(24.25 \%)$ & $614(21.70 \%)$ & $703(25.02 \%)$ & \\
\hline Male & $\begin{array}{l}2108 \\
(74.67 \%)\end{array}$ & $\begin{array}{l}2137 \\
(75.75 \%)\end{array}$ & $\begin{array}{l}2216 \\
(78.30 \%)\end{array}$ & $\begin{array}{l}2107 \\
(74.98 \%)\end{array}$ & \\
\hline Age (years) & $\begin{array}{l}60.64 \pm \\
12.63\end{array}$ & $\begin{array}{l}60.40 \pm \\
12.22\end{array}$ & $\begin{array}{l}59.42 \pm \\
11.81\end{array}$ & $\begin{array}{l}59.97 \pm \\
11.50\end{array}$ & $<0.001$ \\
\hline Heart rate (BPM) & $\begin{array}{l}78.71 \pm \\
18.21\end{array}$ & $\begin{array}{l}79.68 \pm \\
19.40\end{array}$ & $\begin{array}{l}80.10 \pm \\
19.08\end{array}$ & $\begin{array}{l}82.93 \pm \\
20.46\end{array}$ & $<0.001$ \\
\hline Weight (kg) & $62.31 \pm 9.36$ & $63.13 \pm 9.71$ & $64.16 \pm 9.77$ & $64.22 \pm 9.59$ & $<0.001$ \\
\hline SBP $(\mathrm{mmHg})$ & $\begin{array}{l}138.49 \pm \\
27.74\end{array}$ & $\begin{array}{l}141.78 \pm \\
28.71\end{array}$ & $\begin{array}{l}140.78 \pm \\
29.49\end{array}$ & $\begin{array}{l}139.85 \pm \\
29.92\end{array}$ & $<0.001$ \\
\hline Hemoglobin (g/dL) & $13.17 \pm 1.99$ & $13.36 \pm 1.97$ & $13.47 \pm 1.99$ & $13.18 \pm 2.09$ & $<0.001$ \\
\hline CK-MB (units/L) & $\begin{array}{l}65.77 \pm \\
83.07\end{array}$ & $\begin{array}{l}71.26 \pm \\
91.22\end{array}$ & $\begin{array}{l}74.03 \pm \\
93.68\end{array}$ & $\begin{array}{l}64.66 \pm \\
88.11\end{array}$ & 0.087 \\
\hline Troponin (ng/mL) & $8.80 \pm 22.86$ & $\begin{array}{l}10.88 \pm \\
24.20\end{array}$ & $\begin{array}{l}11.55 \pm \\
26.99\end{array}$ & $9.33 \pm 22.56$ & 0.471 \\
\hline $\begin{array}{l}\text { Serum Creatinine } \\
\text { (units/L) }\end{array}$ & $1.16 \pm 0.54$ & $1.14 \pm 0.54$ & $1.17 \pm 0.65$ & $1.22 \pm 0.74$ & 0.020 \\
\hline $\mathrm{HDL}-\mathrm{C}(\mathrm{mg} / \mathrm{dL})$ & $\begin{array}{l}49.53 \pm \\
11.04\end{array}$ & $42.65 \pm 8.48$ & $39.06 \pm 8.99$ & $36.09 \pm 9.11$ & $<0.001$ \\
\hline LDL-C (mg/dL) & $\begin{array}{l}125.08 \pm \\
37.83\end{array}$ & $\begin{array}{l}125.05 \pm \\
40.55\end{array}$ & $\begin{array}{l}123.17 \pm \\
40.63\end{array}$ & $\begin{array}{l}118.47 \pm \\
41.81\end{array}$ & $<0.001$ \\
\hline TRIG (mg/dL) & $\begin{array}{l}130.37 \pm \\
60.91\end{array}$ & $\begin{array}{l}129.67 \pm \\
64.97\end{array}$ & $\begin{array}{l}138.14 \pm \\
71.63\end{array}$ & $\begin{array}{l}153.52 \pm \\
84.79\end{array}$ & $<0.001$ \\
\hline
\end{tabular}

BPM: beats per minute. SBP: systolic blood pressure. CK-MB: creatine kinase isoenzymes in the heart. HDL-C: high-density lipoprotein cholesterol. LDL-C: low-density lipoprotein cholesterol. TRIG: triglycerides. PAD: peripheral arterial disease. TIA: transient ischemic attack. STEMI: ST-segment elevation myocardial infarction. LVEF: left-ventricular ejection fraction. LVEF category: $1: \leq 40 \% ; 2$ : 40-70\%; 3: $\geq 70 \% ; 4$ = unknown or not assessed. PCl: percutaneous coronary intervention. CABG: coronary-artery bypass graft surgery. ACEl: angiotensin-converting enzyme inhibitor. ARB: Angiotensin receptor blocker. MACE: major adverse cardiovascular events. CV death: cardiovascular death. 


\begin{tabular}{|c|c|c|c|c|c|}
\hline Characteristic & Q1 (n=2823) & Q2 (n=2821) & Q3 (n=2830) & Q4 (n=2810) & $\begin{array}{l}\mathrm{P}- \\
\text { value }\end{array}$ \\
\hline $\begin{array}{l}\text { Fasting glucose } \\
(\mathrm{mg} / \mathrm{dL})\end{array}$ & $\begin{array}{l}91.78 \pm \\
20.83\end{array}$ & $\begin{array}{l}118.36 \pm \\
24.42\end{array}$ & $\begin{array}{l}148.15 \pm \\
36.61\end{array}$ & $\begin{array}{l}230.90 \pm \\
75.54\end{array}$ & $<0.001$ \\
\hline Smoking or tobacco & $\begin{array}{l}1156 \\
(40.95 \%)\end{array}$ & $860(30.49 \%)$ & $855(30.21 \%)$ & 709 (25.23\%) & $<0.001$ \\
\hline Hypertension & $\begin{array}{l}1132 \\
(40.10 \%)\end{array}$ & $\begin{array}{l}1249 \\
(44.28 \%)\end{array}$ & $\begin{array}{l}1397 \\
(49.36 \%)\end{array}$ & $\begin{array}{l}1424 \\
(50.68 \%)\end{array}$ & $<0.001$ \\
\hline PAD & $18(0.64 \%)$ & $31(1.10 \%)$ & $26(0.92 \%)$ & $44(1.57 \%)$ & 0.006 \\
\hline Prior TIA or stroke & $78(2.76 \%)$ & $66(2.34 \%)$ & $53(1.87 \%)$ & 79 (2.81\%) & 0.079 \\
\hline Diabetes & $652(23.10 \%)$ & $946(33.53 \%)$ & $\begin{array}{l}1556 \\
(54.98 \%)\end{array}$ & $\begin{array}{l}2242 \\
(79.79 \%)\end{array}$ & $<0.001$ \\
\hline STEMI & $\begin{array}{l}1751 \\
(62.03 \%)\end{array}$ & $\begin{array}{l}1884 \\
(66.78 \%)\end{array}$ & $\begin{array}{l}1892 \\
(66.86 \%)\end{array}$ & $\begin{array}{l}1841 \\
(65.52 \%)\end{array}$ & $<0.001$ \\
\hline Heart failure & $181(6.41 \%)$ & $261(9.25 \%)$ & $289(10.21 \%)$ & 309 (11.00\%) & $<0.001$ \\
\hline Cardiac shock & 49 (1.74\%) & $38(1.35 \%)$ & $60(2.12 \%)$ & 95 (3.38\%) & $<0.001$ \\
\hline Cardiac arrest & $26(0.92 \%)$ & $21(0.74 \%)$ & $36(1.27 \%)$ & 38 (1.35\%) & 0.085 \\
\hline Killip class & & & & & $<0.001$ \\
\hline I & $\begin{array}{l}2499 \\
(88.52 \%)\end{array}$ & $\begin{array}{l}2456 \\
(87.06 \%)\end{array}$ & $\begin{array}{l}2429 \\
(85.83 \%)\end{array}$ & $\begin{array}{l}2324 \\
(82.70 \%)\end{array}$ & \\
\hline II & $86(3.05 \%)$ & $157(5.57 \%)$ & $164(5.80 \%)$ & $184(6.55 \%)$ & \\
\hline III & $155(5.49 \%)$ & $168(5.96 \%)$ & $190(6.71 \%)$ & $244(8.68 \%)$ & \\
\hline IV & $83(2.94 \%)$ & $40(1.42 \%)$ & $47(1.66 \%)$ & $58(2.06 \%)$ & \\
\hline LVEF category & & & & & $<0.001$ \\
\hline 1 & $281(9.95 \%)$ & $363(12.87 \%)$ & $408(14.42 \%)$ & 505 (17.97\%) & \\
\hline 2 & $\begin{array}{l}2083 \\
(73.79 \%)\end{array}$ & $\begin{array}{l}1996 \\
(70.76 \%)\end{array}$ & $\begin{array}{l}1971 \\
(69.65 \%)\end{array}$ & $\begin{array}{l}1908 \\
(67.90 \%)\end{array}$ & \\
\hline 3 & $142(5.03 \%)$ & $166(5.88 \%)$ & $191(6.75 \%)$ & $137(4.88 \%)$ & \\
\hline 4 & 317 (11.23\%) & 296 (10.49\%) & 260 (9.19\%) & 260 (9.25\%) & \\
\hline
\end{tabular}

BPM: beats per minute. SBP: systolic blood pressure. CK-MB: creatine kinase isoenzymes in the heart. HDL-C: high-density lipoprotein cholesterol. LDL-C: low-density lipoprotein cholesterol. TRIG: triglycerides. PAD: peripheral arterial disease. TIA: transient ischemic attack. STEMI: ST-segment elevation myocardial infarction. LVEF: left-ventricular ejection fraction. LVEF category: $1: \leq 40 \% ; 2$ : 40-70\%; 3: $\geq 70 \% ; 4$ = unknown or not assessed. PCl: percutaneous coronary intervention. CABG: coronary-artery bypass graft surgery. ACEl: angiotensin-converting enzyme inhibitor. ARB: Angiotensin receptor blocker. MACE: major adverse cardiovascular events. CV death: cardiovascular death. 


\begin{tabular}{|c|c|c|c|c|c|}
\hline Characteristic & Q1 (n=2823) & Q2 (n=2821) & Q3 (n=2830) & Q4 (n=2810) & $\begin{array}{l}\mathrm{P}- \\
\text { value }\end{array}$ \\
\hline $\begin{array}{l}\text { Symptom onset to } \\
\text { arrival (min) }\end{array}$ & $\begin{array}{l}809.61 \pm \\
1263.34\end{array}$ & $\begin{array}{l}763.32 \pm \\
1269.04\end{array}$ & $\begin{array}{l}773.15 \pm \\
1272.50\end{array}$ & $\begin{array}{l}783.14 \pm \\
1292.02\end{array}$ & 0.573 \\
\hline Door to balloon (min) & $\begin{array}{l}538.33 \pm \\
1421.01\end{array}$ & $\begin{array}{l}483.20 \pm \\
1204.73\end{array}$ & $\begin{array}{l}510.32 \pm \\
1513.07\end{array}$ & $\begin{array}{l}511.91 \pm \\
1489.49\end{array}$ & 0.832 \\
\hline Angiography & $\begin{array}{l}1313 \\
(46.51 \%)\end{array}$ & $\begin{array}{l}1942 \\
(68.84 \%)\end{array}$ & $\begin{array}{l}2067 \\
(73.04 \%)\end{array}$ & $\begin{array}{l}1989 \\
(70.78 \%)\end{array}$ & $<0.001$ \\
\hline $\mathrm{PCl}$ & $\begin{array}{l}1000 \\
(35.42 \%)\end{array}$ & $\begin{array}{l}1615 \\
(57.25 \%)\end{array}$ & $\begin{array}{l}1735 \\
(61.31 \%)\end{array}$ & $\begin{array}{l}1640 \\
(58.36 \%)\end{array}$ & $<0.001$ \\
\hline CABG & $8(0.28 \%)$ & $20(0.71 \%)$ & $15(0.53 \%)$ & $14(0.50 \%)$ & 0.162 \\
\hline Aspirin & $\begin{array}{l}2350 \\
(97.31 \%)\end{array}$ & $\begin{array}{l}2595 \\
(97.34 \%)\end{array}$ & $\begin{array}{l}2623 \\
(97.73 \%)\end{array}$ & $\begin{array}{l}2529 \\
(97.49 \%)\end{array}$ & 0.060 \\
\hline Clopidogrel & $\begin{array}{l}2046 \\
(84.72 \%)\end{array}$ & $\begin{array}{l}2120 \\
(79.52 \%)\end{array}$ & $\begin{array}{l}2072 \\
(77.20 \%)\end{array}$ & $\begin{array}{l}2042 \\
(78.72 \%)\end{array}$ & $<0.001$ \\
\hline Ticagrelor & $223(9.23 \%)$ & 347 (13.02\%) & 378 (14.08\%) & 344 (13.26\%) & $<0.001$ \\
\hline Beta blocker & $\begin{array}{l}1392 \\
(57.64 \%)\end{array}$ & $\begin{array}{l}1600 \\
(60.02 \%)\end{array}$ & $\begin{array}{l}1703 \\
(63.45 \%)\end{array}$ & $\begin{array}{l}1607 \\
(61.95 \%)\end{array}$ & $<0.001$ \\
\hline Warfarin & $30(1.24 \%)$ & $48(1.80 \%)$ & $66(2.46 \%)$ & $50(1.93 \%)$ & 0.059 \\
\hline ACEI & 769 (31.84\%) & $963(36.12 \%)$ & 962 (35.84\%) & 873 (33.65\%) & 0.001 \\
\hline ARB & 202 (8.36\%) & $233(8.74 \%)$ & 240 (8.94\%) & $243(9.37 \%)$ & 0.018 \\
\hline Statin & $\begin{array}{l}2340 \\
(96.89 \%)\end{array}$ & $\begin{array}{l}2557 \\
(95.91 \%)\end{array}$ & $\begin{array}{l}2583 \\
(96.24 \%)\end{array}$ & $\begin{array}{l}2513 \\
(96.88 \%)\end{array}$ & 0.222 \\
\hline MACES & $111(3.93 \%)$ & 103 (3.65\%) & 100 (3.53\%) & $154(5.48 \%)$ & $<0.001$ \\
\hline CV death & $75(2.66 \%)$ & $71(2.52 \%)$ & $62(2.19 \%)$ & $115(4.09 \%)$ & $<0.001$ \\
\hline \multicolumn{6}{|c|}{$\begin{array}{l}\text { BPM: beats per minute. SBP: systolic blood pressure. CK-MB: creatine kinase isoenzymes in the heart. } \\
\text { HDL-C: high-density lipoprotein cholesterol. LDL-C: low-density lipoprotein cholesterol. TRIG: } \\
\text { triglycerides. PAD: peripheral arterial disease. TIA: transient ischemic attack. STEMI: ST-segment } \\
\text { elevation myocardial infarction. LVEF: left-ventricular ejection fraction. LVEF category: } 1: \leq 40 \% ; 2 \text {; } \\
\text { 40-70\%; 3: } \geq 70 \% ; 4 \text { = unknown or not assessed. PCl: percutaneous coronary intervention. CABG: } \\
\text { coronary-artery bypass graft surgery. ACEl: angiotensin-converting enzyme inhibitor. ARB: Angiotensin } \\
\text { receptor blocker. MACE: major adverse cardiovascular events. CV death: cardiovascular death. }\end{array}$} \\
\hline
\end{tabular}

\section{Results}

\section{Baseline characteristics of participants}

All patients were subdivided into four quartiles according to the FG/HDL-C ratio levels. Table 1 shows the baseline characteristics of the study population according to the FG/HDL-C ratio quartiles. Briefly, a total 
of 11,284 patients (8,568 male patients and 2,716 female patients) were available for the final baseline analysis. Their age was $60.11 \pm 12.05$ years; 5,202 patients $(46.10 \%)$ had a history of hypertension, and $5,396(47.82 \%)$ had a history of diabetes. The FG/HDL-C ratio was $3.75 \pm 2.05$. There were statistically significant differences $(P<0.05)$ among the four quartiles in terms of intervention, sex, age, heart rate, weight, SBP, hemoglobin, sCr, HDL-C, LDL-C, TRIG, FG, smoking or tobacco, hypertension, PAD, diabetes, STEMI, heart failure, cardiac shock, Killip class, LVEF category, angiography, PCl, and the use of medications including clopidogrel, ticagrelor, beta-blocker, ACEI, and ARB. No statistically significant differences were found for the other indicators. Patients with FG/HDL-C ratio levels in the highest quartile had higher levels of sCr and FG and lower levels of HDL-C and LDL-C, had a higher incidence of hypertension, PAD, diabetes, heart failure, and cardiac shock, and fewer of them smoked.

\section{Relationship between FG/HDL-C ratio and adverse outcomes}

The multivariable stepwise analysis of the three models (non-adjusted model, minor-adjusted model, and fully adjusted model) is shown in Tables 2 . The FG/HDL-C ratio was significantly associated with an increased risk of MACEs in patients in the highest quartile (non-adjusted model, odds ratio [OR]: 1.42; 95\% confidence interval [CI], [1.10, 1.82]; P< 0.01) (minor-adjusted model, OR: 1.57; 95\% Cl, [1.21, 2.03]; $\mathrm{P}<$ 0.01 ) (fully adjusted model, OR: $1.49 ; 95 \% \mathrm{Cl},[1.11,1.99] ; \mathrm{P}<0.01$ ). Regarding $\mathrm{CV}$ death, patients in the highest quartile had the highest risk (non-adjusted model, OR: 1.56; $95 \% \mathrm{Cl},[1.16,2.10]$; $\mathrm{P}<0.01$ ) (minoradjusted model, OR: 1.77; 95\% Cl, [1.30, 2.39]; $\mathrm{P}<0.01$ ) (fully adjusted model, OR: 1.69; 95\% Cl, [1.01, $1.41) ; P=0.04$ ) compared with those in the lowest quartile. When we used the FG/HDL-C ratio as a continuous covariate, in the non-adjusted model, the risk of MACEs and CV death increased as the FG/HDL-C ratio increased (MACEs, OR: 1.09; 95\% Cl, [1.05, 1.13]; $\mathrm{P}<0.01$ ) (CV death, OR: $1.11 ; 95 \% \mathrm{Cl}$, $[1.07,1.16) ; P<0.01)$. In the minor-adjusted model, there was no significant change in the results after adjustment (MACEs, OR: 1.10; 95\% Cl, [1.06, 1.15]; $\mathrm{P}<0.01$ ) (CV death, OR: 1.13; 95\% Cl, $[1.08,1.18$ ); $\mathrm{P}<$ 0.01). In the fully adjusted model, fully adjusting for confounders also did not change the trend (MACEs, OR: 1.09; 95\% Cl, $[1.04,1.14] ; \mathrm{P}<0.01$ ) (CV death, OR: 1.11; 95\% Cl, $[1.04,1.19) ; \mathrm{P}<0.01$ ).

Table 2. Relationship between the FG/HDL-C ratio and short-term outcomes in different models. 


\section{MACEs}

\begin{tabular}{|c|c|c|c|}
\hline Exposure & Non-adjusted & Minor-adjusted & Fully adjusted \\
\hline $\mathrm{FG} / \mathrm{HDL}-\mathrm{C}$ ratio & $\begin{array}{l}1.09(1.05,1.13), P< \\
0.01\end{array}$ & $\begin{array}{l}1.10(1.06,1.15), P< \\
0.01\end{array}$ & $\begin{array}{l}1.09(1.04,1.14), P< \\
0.01\end{array}$ \\
\hline \multicolumn{4}{|l|}{$\begin{array}{l}\text { FG/HDL-C ratio } \\
\text { grouping }\end{array}$} \\
\hline Q1 & Ref & Ref & Ref \\
\hline Q2 & $\begin{array}{l}0.93(0.70,1.22), P= \\
0.58\end{array}$ & $\begin{array}{l}0.95(0.72,1.26), P= \\
0.75\end{array}$ & $\begin{array}{l}0.98(0.73,1.30), P= \\
0.88\end{array}$ \\
\hline Q3 & $\begin{array}{l}0.89(0.68,1.18), P= \\
0.43\end{array}$ & $\begin{array}{l}1.00(0.76,1.33), P= \\
0.98\end{array}$ & $\begin{array}{l}1.03(0.76,1.38), P= \\
0.86\end{array}$ \\
\hline \multirow[t]{2}{*}{ Q4 } & $\begin{array}{l}1.42(1.10,1.82), P< \\
0.01\end{array}$ & $\begin{array}{l}1.57(1.21,2.03), P< \\
0.01\end{array}$ & $\begin{array}{l}1.49(1.11,1.99), \mathrm{P}< \\
0.01\end{array}$ \\
\hline & CV death & & \\
\hline Exposure & Non-adjusted & Minor-adjusted & Fully adjusted \\
\hline FG/HDL-C ratio & $\begin{array}{l}1.11(1.07,1.16), P< \\
0.01\end{array}$ & $\begin{array}{l}1.13(1.08,1.18), P< \\
0.01\end{array}$ & $\begin{array}{l}1.11(1.04,1.19), \mathrm{P}< \\
0.01\end{array}$ \\
\hline \multicolumn{4}{|l|}{$\begin{array}{l}\mathrm{FG} / \mathrm{HDL}-\mathrm{C} \text { ratio } \\
\text { grouping }\end{array}$} \\
\hline Q1 & Ref & Ref & Ref \\
\hline Q2 & $\begin{array}{l}0.95(0.68,1.31), P= \\
0.74\end{array}$ & $\begin{array}{l}0.98(0.70,1.38), P= \\
0.92\end{array}$ & $\begin{array}{l}1.01(0.59,1.71), P= \\
0.98\end{array}$ \\
\hline Q3 & $\begin{array}{l}0.82(0.58,1.15), P= \\
0.26\end{array}$ & $\begin{array}{l}0.94(0.66,1.33), P= \\
0.71\end{array}$ & $\begin{array}{l}0.83(0.48,1.46), P= \\
0.53\end{array}$ \\
\hline Q4 & $\begin{array}{l}1.56(1.16,2.10), P< \\
0.01\end{array}$ & $\begin{array}{l}1.77(1.30,2.39), P< \\
0.01\end{array}$ & $\begin{array}{l}1.69(1.01,1.41), P= \\
0.04\end{array}$ \\
\hline
\end{tabular}

Co-linearity analysis showed that $\mathrm{FG}$, cardiac arrest, $\mathrm{PCl}, \mathrm{CABG}$ and $\mathrm{FG} / \mathrm{HDL}-\mathrm{C}$ ratio had high co-linearity. Therefore, FG, cardiac arrest, $\mathrm{PCl}$, and CABG weren't included in multivariate model.

For MACEs, in the non-adjusted model, we did not adjust other covariates. In the minor-model, we adjusted for cohort, intervention, age, and sex. In the fully model, we adjusted for cohort, intervention, age, sex, heart rate, weight, SBP, hemoglobin, TRIG, smoking or tobacco, hypertension, prior TIA or stroke, diabetes, heart failure, cardiac shock, Killip class, LVEF category.

For CV death, in the non-adjusted model, we did not adjust other covariates. In the minor-model, we adjusted for cohort, intervention, age, and sex. In the fully model, we adjusted for cohort, intervention, age, 
sex, weight, heart rate, troponin, TRIG, smoking or tobacco, hypertension, diabetes, heart failure, cardiac shock, Killip class, LVEF category, symptom onset to arrival.

\section{Analyses of non-linear relationship}

The GAM suggested non-linear relationships between the FG/HDL-C ratio and MACEs and CV death according to the equivalent degrees of freedom of GAM which were 1.03 for MACEs and 1.14 for CV death (Figure $1(A)$ and $(B)$ ). We used two-piecewise linear regression models to characterize the relationship (Table 3). In addition, we identified 3.02 and 3.00 as the threshold values for MACEs and CV death, respectively. Below these threshold values, the FG/HDL-C ratio was not associated with MACEs or $\mathrm{CV}$ death. However, above these threshold values, the FG/HDL-C ratio increased, and the risk of MACEs and CV death increased (MACEs, OR: 1.12; 95\% Cl, [1.07, 1.17]; $\mathrm{P}<0.01$; CV death, OR: $1.15 ; 95 \% \mathrm{Cl},[1.09$, 1.20]; $P<0.01$ ).

Table 3

Results of two-piecewise linear-regression model.

\section{Outcome: MACEs}

Exposure: FG/HDL-C

ratio

One linear-regression

model

Inflection point (K)

$<$ K Effect size $\beta$

$(95 \% \mathrm{Cl})$

$>$ K Effect size $\beta$

$(95 \% \mathrm{Cl})$

P for Log likelihood ratio test

\section{Outcome: CV death}

Exposure: FG/HDL-C

ratio

$1.09(1.05,1.13), \mathrm{P}<\quad$ One linear-regression

0.01

model

$1.11(1.07,1.16), \mathrm{P}<$

0.01

Inflection point (K)

3.00

$<$ K Effect size $\beta$

$(95 \% \mathrm{Cl})$

$0.85(0.67,1.08), P=$

0.20

$>$ K Effect size $\beta$

$(95 \% \mathrm{Cl})$

$1.15(1.09,1.20), \mathrm{P}<$

0.01

P for Log likelihood

ratio test

\section{(A) (B)}

(A) MACEs: major adverse cardiovascular events and (B) CV death: cardiovascular death. The twopiecewise linear regression model was used to calculate the threshold effect.

\section{Subgroup analysis and interaction test}

The results of the stratified analysis are illustrated in Supplementary Figures 1 and 2. For MACEs, the significant variable in the interaction test was CABG $(P<0.01)$. The OR without CABG was less than that with CABG (1.09 vs. 2.59), and the $95 \%$ Cls did not overlap (1.04, 1.13; $P<0.01$ vs. $1.17,5.72 ; P=0.02)$. For $\mathrm{CV}$ death, the significant variable in the interaction test was age $(P<0.05)$. The ORs of patients aged $\geq 75$ years were less than those of patients aged $<75$ years ( 1.04 vs. 1.15 ); however, the $95 \%$ Cls 
overlapped $(1.10,1.21 ; P<0.01$ vs. $0.95,1.14 ; P=0.39)$. A high FG/HDL-C ratio indicated a higher risk of MACEs in patients with CABG than in patients without CABG (Figure 2 (C)). In those aged $<75$ years, a high FG/HDL-C ratio indicated a higher risk of CV death than in patients aged $\geq 75$ years (Figure 2 (D)).

\section{Discussion}

We investigated the association between the FG/HDL-C ratio and MACEs and CV death in patients undergoing ACS. Our study demonstrated for the first time that the incidence of MACEs and CV death within 30 days after admission was higher among patients with ACS with FG/HDL-C ratios in the highest quartile. For MACEs, the inflection point was 3.02; when the FG/HDL-C ratio was $>3.02$, the incidence of MACEs increased by $12 \%$ for every increase of 1 in the FG/HDL-C ratio. For CV death, the inflection point was 3.00; when the FG/HDL-C ratio was $>3.00$, the incidence of CV death increased by $15 \%$ for every increase of 1 in the FG/HDL-C ratio. Therefore, a higher FG/HDL-C ratio was associated with a higher incidence of MACEs and CV death in patients with ACS.

During the pathophysiological process leading to CADs, glycoxidation products from hyperglycemia result in superoxide overproduction in arterial endothelial cells leading to inflammation and impaired endothelial function (20). Meanwhile, when arterial endothelial cells encounter dyslipidemia, adhesion molecule expression is augmented, and the adhesion of blood leukocytes to the inner surface of the arterial wall is promoted (21). Hyperglycemia and low HDL levels are known risk factors that are significantly associated with adverse outcomes in patients with ACS. Farhan et al. reported that among patients with high-risk non-STEMI ACS, for every $1 \mathrm{mg} / \mathrm{dL}$ increase in FG, the hazard ratio (HR) for 1-year death increased by $53 \%$ (22). Similar findings were reported by other investigators; Ramos et al. demonstrated that FG is associated with MACEs in older and younger patient groups ( $<65$ years and $\geq 65$ years) (23). However, the number of patients included in the study was relatively small, only 580 patients. Statin, a lipid-lowering drug, is widely prescribed for the treatment of CVD. Statin treatment slightly increases serum HDL-C levels; however, in some clinical settings, there is a paradoxical decrease in HDL-C levels. In a previous study, the HR for MACEs increased by $56 \%$ for every $1 \mathrm{mg} / \mathrm{dL}$ reduction in HDL-C in patients initiated on statin treatment (24). Similarly, Hirayama et al. demonstrated that compared with LDL-C levels, HDL-C levels were more strongly associated with the incidence of MACEs, especially in patients with stable angina pectoris (25). The follow-up in the trial of Hirayama et al. was up to 7 years. Overall, these findings extend the previously reported findings from other investigators. As a composite indicator, the FG/HDL-C ratio consists of two major indicators: both FG and HDL-C are associated with poor prognosis in patients with ACS. However, whether the combined effect of the two indicators is greater than a single indicator remained unclear. Therefore, we assessed the association between the FG/HDL-C ratio and 30-day MACEs and 30-day CV death.

In recent years, several novel biomarkers have been reported, including microRNAs (26) and long noncoding ribonucleic acids (27). However, measuring these biomarkers is expensive, time-consuming, and complicated. Therefore, a number of limitations should be considered when searching for better biomarkers. In intensive biomarker research studies, some biomarkers showed statistically significant 
results for adverse outcomes in patients with CAD, such as red blood cell distribution width (28), gammaglutamyl transferase-to-platelet ratio (29), mean platelet volume (30), monocyte-to-HDL ratio (31), triglyceride/HDL-C ratio (15), and triglyceride-glucose index (16). These biomarkers are more accessible, convenient, and economical and can serve to supplement traditional prognostic indicators and provide new information for clinical assessment and treatment; however, their sensitivity and specificity vary.

Recently, the relationship between the FG/HDL-C ratio and clinical adverse outcomes was studied in patients without diabetes after $\mathrm{PCl}$ (32). The findings suggested that the incidence of all-cause mortality increased by $28.4 \%$ in patients with a higher FG/HDL-C ratio (HR: 1.284; 95\% $\mathrm{Cl}$, $[1.010,1.631]$; $\mathrm{P}<0.05$ ). However, few studies have been conducted on the FG/HDL-C ratio in other populations. Therefore, in our study, we focused on the ACS population, regardless of whether they had diabetes. Our multivariate logistic regression analysis showed that an increased FG/HDL-C ratio was associated with MACEs and $\mathrm{CV}$ death, which is in agreement with the findings of Guo et al. (32). However, it is worth mentioning that further subgroup analyses in our study suggested that the ORs of patients with diabetes were less than those of patients with diabetes for MACEs, and the ORs of patients with diabetes were higher than those of patients with diabetes for CV death (MACEs, 1.08 vs 1.09; CV death, 1.11 vs. 1.10), although the interaction did not reach statistical significance.

In the present study, we analyzed more than 10,000 patients with ACS in India. All patients were divided into four groups according to their FG/HDL-C ratio levels. In the baseline characteristic analysis, several baseline characteristics were significantly different between the four groups, and there may have been some unmeasured differences between the four groups. Considering the effect of these confounders, we performed multivariate logistic regression analysis to reduce the effect of the confounders; however, the ORs were not substantially altered. After the subgroup analysis, our data showed that the increased risk of MACEs was more pronounced in patients undergoing CABG, and the increased risk of CV death was more pronounced in patients aged $<75$ years. Based on these findings, our study highlights some aspects of the management of patients with ACS, and we should pay close attention to patients with ACS undergoing $C A B G$ and aged $<75$ years with a high $F G / H D L-C$ ratio.

Our study had several limitations. First, to minimize the effect of confounders, we adjusted for many variables as completely as possible; however, because of the incompleteness of the original data, we cannot ensure that all confounding variables were fully adjusted. Second, some patients did not undergo coronary angiography or $\mathrm{PCl}$ because of patients' refusal or poor clinical condition, resulting in a lower perfusion rate after primary angioplasty which may have impacted our results to a certain extent. Third, because we used data from hospitals in Kerala, India, the external validity of our results is limited. Moreover, the follow-up time was only 30 days, and a longer follow-up time might have affected the results. Finally, the key limitation is that a large number of patients, approximately the $50 \%$, was excluded from the present study due to missing data.

\section{Conclusions}


In conclusion, our study demonstrated that the FG/HDL-C ratio may be an accessible, convenient, and economical biomarker of short-term outcomes in patients with ACS and could be used to guide their clinical management.

\section{Abbreviations}

CAD

coronary artery disease

FG

fasting blood glucose

HDL-C

high-density lipoprotein cholesterol

ACS

acute coronary syndrome

MACEs

major adverse cardiovascular events

CV

cardiovascular

ACS-QUIK

acute coronary syndrome quality improvement in Kerala

GAM

generalized additive model

MetS

metabolic syndrome

TRIG

triglycerides

SBP

systolic blood pressure

CK-MB

creatine kinase isoenzymes in the heart

$\mathrm{sCr}$

serum creatinine

LDL-C

low-density lipoprotein cholesterol

PAD

peripheral arterial disease

TIA

transient ischemic attack

STEMI

ST-segment elevation myocardial infarction 
LVEF

left ventricular ejection fraction

$\mathrm{PCl}$

percutaneous coronary intervention

CABG

coronary artery bypass graft surgery

ACEI

angiotensin-converting enzyme inhibitor

ARB

angiotensin receptor blocker

SD

standard deviation

\section{Declarations}

Ethics approval and consent to participate

No applicable

\section{Consent for publication}

No applicable

\section{Availability of data and materials}

Data are available from the Biologic Specimen and Data Repository Information Coordinating Center (BioLINCC).

\section{Competing interests}

The authors have no conflict of interest to declare.

\section{Funding}

This paper received no funding.

\section{Author contributions}

Xinqun Hu and Simin Deng designed the study and provided methodological expertise. Simin Deng drafted the manuscript. Simin Deng, Zhaojun Wang, Yifeng Zhang, and Ying Xin drafted the tables and figures and performed statistical analysis. Cheng Zeng revised the manuscript. All authors have read and approved the final manuscript.

\section{Acknowledgements}


The authors would like to acknowledge Editage Language Services for providing language assistance and proofreading the manuscript.

\section{References}

1. Libby P, Theroux P. Pathophysiology of coronary artery disease. Circulation. 2005;111(25):3481-8.

2. Agrawal H, Choy HK, Liu J, Auyoung M, Albert MA. Coronary Artery Disease. Arteriosclerosis, thrombosis, and vascular biology. 2020;40(7):e185-e92.

3. Kandaswamy E, Zuo L. Recent Advances in Treatment of Coronary Artery Disease: Role of Science and Technology. International journal of molecular sciences. 2018;19(2).

4. Vedanthan R, Seligman B, Fuster V. Global perspective on acute coronary syndrome: a burden on the young and poor. Circulation research. 2014;114(12):1959-75.

5. Eckel RH, Grundy SM, Zimmet PZ. The metabolic syndrome. Lancet (London, England). 2005;365(9468):1415-28.

6. Kassi E, Pervanidou P, Kaltsas G, Chrousos G. Metabolic syndrome: definitions and controversies. BMC medicine. 2011;9:48.

7. Lakka HM, Laaksonen DE, Lakka TA, Niskanen LK, Kumpusalo E, Tuomilehto J, et al. The metabolic syndrome and total and cardiovascular disease mortality in middle-aged men. Jama. 2002;288(21):2709-16.

8. Mehta RH, Westerhout CM, Zheng Y, Giugliano RP, Huber K, Prabhakaran D, et al. Association of metabolic syndrome and its individual components with outcomes among patients with high-risk non-ST-segment elevation acute coronary syndromes. American heart journal. 2014;168(2):182-8.e1.

9. Malik S, Wong ND, Franklin SS, Kamath TV, L'Italien GJ, Pio JR, et al. Impact of the metabolic syndrome on mortality from coronary heart disease, cardiovascular disease, and all causes in United States adults. Circulation. 2004;110(10):1245-50.

10. Mente A, Yusuf S, Islam S, McQueen MJ, Tanomsup S, Onen CL, et al. Metabolic syndrome and risk of acute myocardial infarction a case-control study of 26,903 subjects from 52 countries. Journal of the American College of Cardiology. 2010;55(21):2390-8.

11. Kolman L, Hu YC, Montgomery DG, Gordon K, Eagle KA, Jackson EA. Prognostic value of admission fasting glucose levels in patients with acute coronary syndrome. The American journal of cardiology. 2009;104(4):470-4.

12. Cid-Alvarez B, Gude F, Cadarso-Suarez C, Gonzalez-Babarro E, Rodriguez-Alvarez MX, Garcia-Acuna $\mathrm{JM}$, et al. Admission and fasting plasma glucose for estimating risk of death of diabetic and nondiabetic patients with acute coronary syndrome: nonlinearity of hazard ratios and timedependent comparison. American heart journal. 2009;158(6):989-97.

13. Younis A, Goldkorn R, Goldenberg I, Geva D, Tzur B, Mazu A, et al. Impaired Fasting Glucose Is the Major Determinant of the 20-Year Mortality Risk Associated With Metabolic Syndrome in Nondiabetic 
Patients With Stable Coronary Artery Disease. Journal of the American Heart Association. 2017;6(11).

14. Silbernagel G, Schöttker B, Appelbaum S, Scharnagl H, Kleber ME, Grammer TB, et al. High-density lipoprotein cholesterol, coronary artery disease, and cardiovascular mortality. European heart journal. 2013;34(46):3563-71.

15. Sultani R, Tong DC, Peverelle M, Lee YS, Baradi A, Wilson AM. Elevated Triglycerides to High-Density Lipoprotein Cholesterol (TG/HDL-C) Ratio Predicts Long-Term Mortality in High-Risk Patients. Heart, lung \& circulation. 2020;29(3):414-21.

16. Mao Q, Zhou D, Li Y, Wang Y, Xu SC, Zhao XH. The Triglyceride-Glucose Index Predicts Coronary Artery Disease Severity and Cardiovascular Outcomes in Patients with Non-ST-Segment Elevation Acute Coronary Syndrome. Disease markers. 2019;2019:6891537.

17. Huffman MD, Mohanan PP, Devarajan R, Baldridge AS, Kondal D, Zhao L, et al. Acute coronary syndrome quality improvement in Kerala (ACS QUIK): Rationale and design for a cluster-randomized stepped-wedge trial. American heart journal. 2017;185:154-60.

18. Huffman MD, Mohanan PP, Devarajan R, Baldridge AS, Kondal D, Zhao L, et al. Effect of a Quality Improvement Intervention on Clinical Outcomes in Patients in India With Acute Myocardial Infarction: The ACS QUIK Randomized Clinical Trial. Jama. 2018;319(6):567-78.

19. Thygesen K, Alpert JS, Jaffe AS, Simoons ML, Chaitman BR, White HD, et al. Third universal definition of myocardial infarction. Circulation. 2012;126(16):2020-35.

20. Laakso M, Kuusisto J. Insulin resistance and hyperglycaemia in cardiovascular disease development. Nature reviews Endocrinology. 2014;10(5):293-302.

21. Kopin L, Lowenstein C. Dyslipidemia. Annals of internal medicine. 2017;167(11):Itc81-itc96.

22. Farhan S, Clare RM, Jarai R, Giugliano RP, Lokhnygina Y, Harrington RA, et al. Fasting glucose, NTproBNP, treatment with eptifibatide, and outcomes in non-ST-segment elevation acute coronary syndromes: An analysis from EARLY ACS. International journal of cardiology. 2017;232:264-70.

23. Ramos AM, Pellanda LC, Vieira PL, Ribeiro DP, Menti E, Portal VL. Prognostic value of fasting glucose levels in elderly patients with acute coronary syndrome. Arquivos brasileiros de cardiologia. 2012;98(3):203-10.

24. Hasvold P, Thuresson M, Sundström J, Hammar N, Kjeldsen SE, Johansson G, et al. Association Between Paradoxical HDL Cholesterol Decrease and Risk of Major Adverse Cardiovascular Events in Patients Initiated on Statin Treatment in a Primary Care Setting. Clinical drug investigation. 2016;36(3):225-33.

25. Hirayama K, Ota T, Harada K, Shibata Y, Tatami Y, Harata S, et al. Impact of Paradoxical Decrease in High-density Lipoprotein Cholesterol Levels After Statin Therapy on Major Adverse Cardiovascular Events in Patients with Stable Angina Pectoris. Clinical therapeutics. 2017;39(2):279-87.

26. Kaur A, Mackin ST, Schlosser K, Wong FL, Elharram M, Delles C, et al. Systematic review of microRNA biomarkers in acute coronary syndrome and stable coronary artery disease. Cardiovascular research. 2020;116(6):1113-24. 
27. Agwa SHA, Elzahwy SS, El Meteini MS, Elghazaly H, Saad M, Abd Elsamee AM, et al. ABHD4Regulating RNA Panel: Novel Biomarkers in Acute Coronary Syndrome Diagnosis. Cells. 2021;10(6).

28. Wu TT, Zheng YY, Hou XG, Yang Y, Ma X, Ma YT, et al. Red blood cell distribution width as long-term prognostic markers in patients with coronary artery disease undergoing percutaneous coronary intervention. Lipids in health and disease. 2019;18(1):140.

29. Zheng YY, Wu TT, Chen Y, Hou XG, Yang Y, Ma X, et al. Gamma-Glutamyl Transferase-to-Platelet Ratio as a Novel Predictor of Long-Term Adverse Outcomes in Patients after Undergoing Percutaneous Coronary Intervention: A Retrospective Cohort Study. Thrombosis and haemostasis. 2019;119(6):1021-30.

30. Wada H, Dohi T, Miyauchi K, Shitara J, Endo H, Doi S, et al. Mean platelet volume and long-term cardiovascular outcomes in patients with stable coronary artery disease. Atherosclerosis. 2018;277:108-12.

31. Ganjali S, Gotto AM, Jr., Ruscica M, Atkin SL, Butler AE, Banach M, et al. Monocyte-to-HDL-cholesterol ratio as a prognostic marker in cardiovascular diseases. Journal of cellular physiology. 2018;233(12):9237-46.

32. Guo QQ, Zheng YY, Tang JN, Wu TT, Yang XM, Zhang ZL, et al. Fasting blood glucose to HDL-C ratio as a novel predictor of clinical outcomes in non-diabetic patients after PCl. Bioscience reports. 2020;40(12).

\section{Figures}




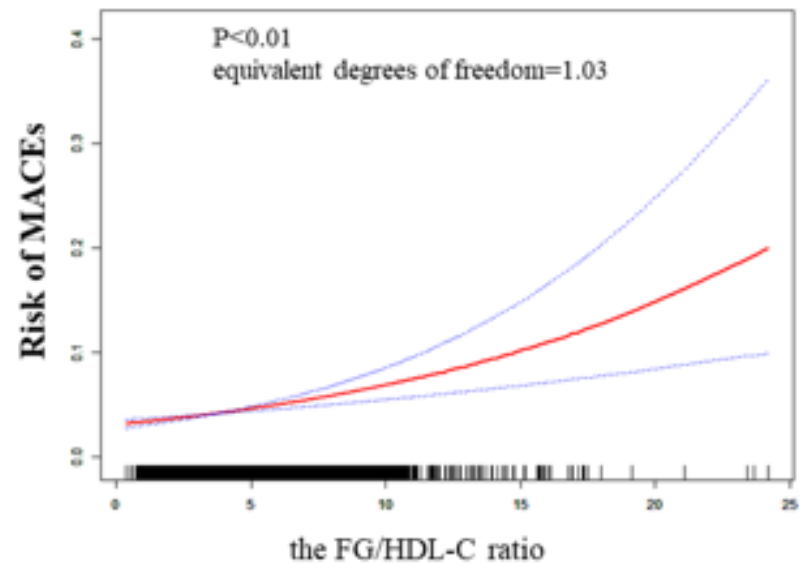

(A)

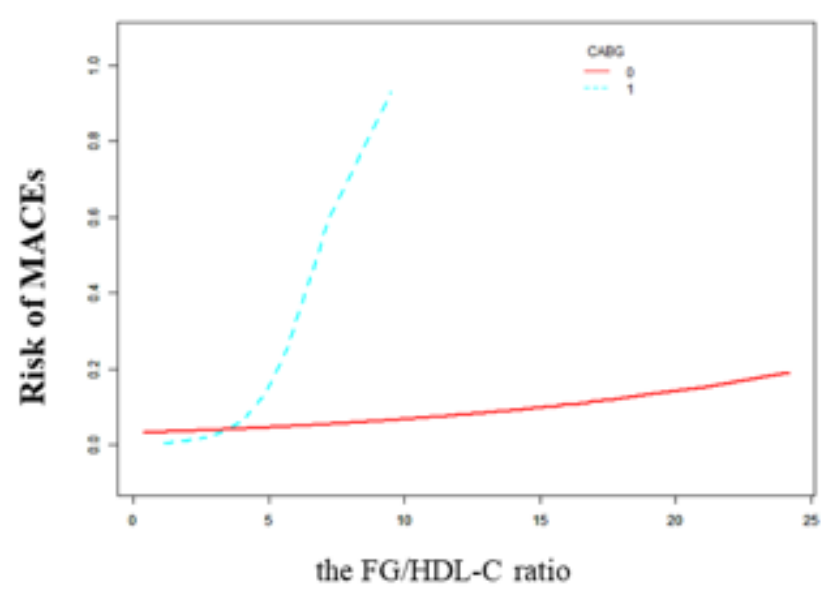

(C)

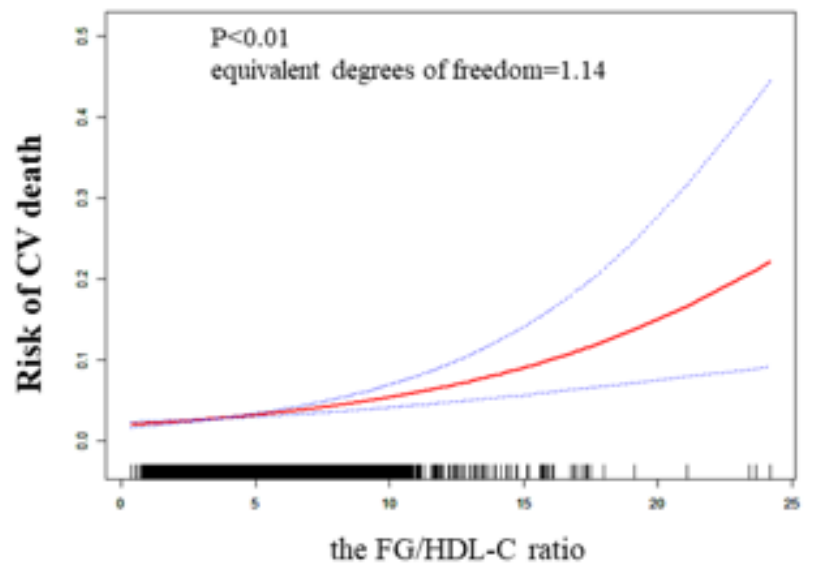

(B)

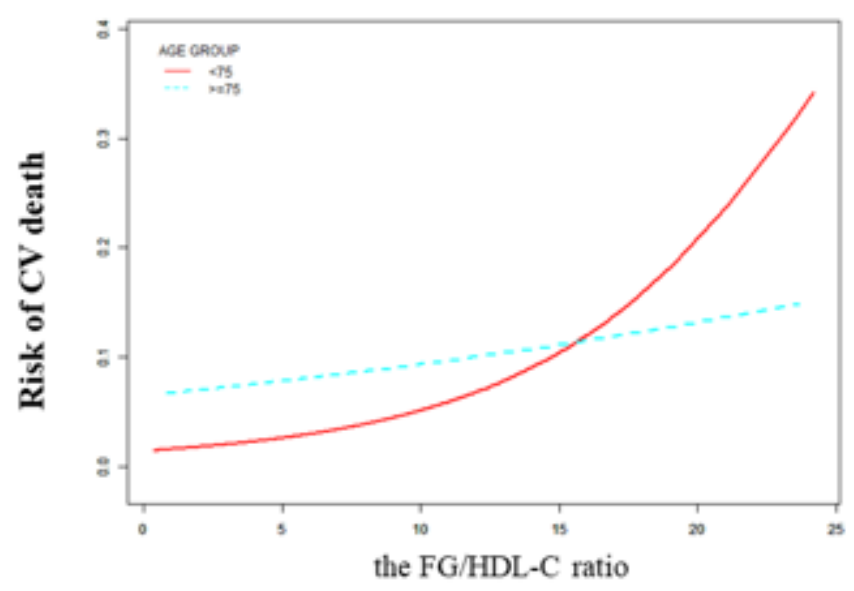

(D)

\section{Figure 1}

Relationship between the FG/HDL-C ratio and MACEs (A), and CV death (B); Relationship between the FG/HDL-C ratio and MACEs grouped by CABG (C), and CV death grouped by age (D). The red line is the trend line, and the blue line is the $95 \%$ confidence interval. The denser the vertical lines, the greater the number of patients in the area. CABG 0: without CABG, CABG 1: with CABG.

\section{Supplementary Files}

This is a list of supplementary files associated with this preprint. Click to download.

- supplementarymaterial.docx 